\title{
Um olhar sobre o flagelo do novo coronavirus em chave apocalíptica: uma reflexão teológica de Ap 6,1-8
}

\author{
A look at the scourge of the new coronavirus disease in \\ apocaliptic key: \\ a theological reflection upon Revelation 6,1-8
}

Gilvan Leite de Araujo

Izabel Patuzzo

\section{Resumo}

Desde o início da pandemia, provocada pela disseminação do Covid-19, há inúmeras reflexões sobre sua origem, mudanças e transformações por ela provocadas. O impacto deste flagelo, com dimensões globais, provocou uma paralização nas mais diversas atividades socioeconômicas. O presente artigo propõe, primeiramente, uma reflexão teológico-cristã sobre flagelos que assolam a humanidade sob a perspectiva da literatura do Apocalipse de João. Em tal literatura, os flagelos não eram castigo divino, mas resultado das más ações humanas. Este olhar era uma forma de resistência, buscando reconstruir a esperança dos discípulos de Jesus Cristo, em um período de grandes sofrimentos. Os dois pontos seguintes, inspirados na visão apocalítica, refletem sobre algumas possíveis causas da atual Pandemia. Ambientalistas e profissionais de diversos âmbitos da saúde têm alertado autoridades políticas e econômicas há décadas, acerca desses riscos. Buscando luzes na postura crítica e de resistência da literatura apocalíptica, o artigo pretende destacar que os movimentos que deram origem a esses escritos apontam caminhos de compreensão para as verdadeiras causas dos flagelos numa perspectiva de fé, a fim de preservar a vida e construir um mundo mais fraterno e solidário.

Palavras-chave: Pandemia. Apocalipse. Resistencia. Esperança. Flagelo. 


\begin{abstract}
Since the beginning of the pandemic, caused by the dissemination of Covid-19, there have been reflections on its origin, changes and transformations caused by it. The impact of this scourge, with global dimensions, caused a halt in the most diverse socioeconomic activities. This article proposes, first, a Christian-theological reflection on the scourges that plague humanity from the perspective of the literature of Revelation of Jonh. In such literature, the scourges was not divine punishment, but the result of human misdeeds. This look was a form of resistance, seeking to rebuild the hope of the disciples of Jesus Christ, in a period of great suffering. The next two points, inspired by the apocalyptic vision, reflect on some possible causes of the current pandemic. Environmentalists and professionals from different areas of health have been warning political and economic authorities for decades about these risks. Seeking insights into the critical stance and resistance of apocalyptic literature, the article intends to highlight that the movements that gave rise to these writings point to ways of understanding the true causes of the scourges from a perspective of faith in view of preserving life and build a more fraternal and solidary world.
\end{abstract}

Keywords: Pandemic. Revelation. Resistance. Hope. Scourge.

\title{
Introdução
}

A Pandemia, que assolou o mundo nestes últimos tempos, surgiu como uma assustadora surpresa. O flagelo, causado pela Covid-19, desafia os cientistas, as políticas e organizações sociopolíticas em nível global. A Igreja também foi desafiada, no seu cuidado pastoral, a defender a vida, como dom de Deus e a buscar sentido nesta calamidade que se abateu sobre a humanidade. Ela busca refletir, principalmente, sobre o modo como temos tratado a natureza e todas as criaturas, visto que todos dependemos de um meio ambiente saudável. A partir da perspectiva da fé em Jesus Cristo, a Palavra de Deus nos ajuda iluminar essa realidade e adotar atitudes que possam contribuir para sua superação.

Este artigo se propõe a uma reflexão teológica-cristã sobre flagelos que assolam a humanidade sob a perspectiva da literatura do Apocalipse de São João. Ele ofereceu às comunidades da Ásia Menor, no final do primeiro século 
da era cristã, uma chave de interpretação para os flagelos de seu tempo, a partir de Jesus Cristo. A leitura dos fatos, segundo a fé em Jesus Cristo, nos permite desvendar as origens daqueles acontecimentos e, ao mesmo tempo, manter viva a esperança de superação destes.

A explosão da disseminação da Covid-19 tem provocado uma série de outros fatores, como crise econômica, desemprego, fome, morte, isolamento, sofrimento físico, emocional e espiritual a milhares de pessoas. Esta situação, por um tempo tão prolongado, afronta nossa fé cristã no sentido de como cuidar e preservar a vida das pessoas enquanto estão com saúde e, também, do meio ambiente, nossa casa comum, como nos lembra o Papa Francisco.

\section{A Linguagem Apocalíptica}

Nos escritos neotestamentários, o livro do Apocalipse se distingue, enquanto gênero literário. Seu autor, o vidente de Patmos, que se apresenta apenas como João, abraça um gênero específico com elementos da apocalíptica, profecia elaborada numa carta pastoral e dirigida às sete Igrejas da Ásia Menor. ${ }^{1}$

A ênfase da narrativa apocalíptica do livro pressupõe uma capacidade imaginativa, da qual não se trata de decodificar símbolos, mas de entrar em um mundo privado e subjetivo, para além do racional científico. ${ }^{2}$ João prefere um estilo narrativo dramático, com símbolos do universo, que se movem como uma espiral, partindo do presente para um futuro escatológico. ${ }^{3}$ Dentre os Escritos do Novo Testamento, o Apocalipse de João permanece como um estilo profético-sapiencial, quase que isolado, com a finalidade de proclamar e exaltar Jesus Cristo, o Cordeiro de Deus glorioso, aos cristãos das comunidades que pastoreia.

O Apocalipse surge, pois, em resposta ao desejo e necessidade de compartilhar a experiência de uma visão cristã do mundo. E, se constitui também, como um estilo literário de afronta, diante dos flagelos sociais e religiosos pelos quais passavam as comunidades cristãs de então; ante o contexto absolutista do Império Romano em toda sua forma de governar, que constituía uma verdadeira ameaça à identidade cristã ${ }^{4}$ aos valores éticos como justiça, dignidade para todos, cuidado com os empobrecidos e o reconhecimento de Deus como única divindade.

\footnotetext{
${ }^{1}$ GONZAGA, W., Ap 19,1-8, p. 567.

${ }^{2}$ GIRBÉS, E. A., El Apocalipsis de San Juan, p. 22.

${ }^{3}$ FIORENZA, E. S., The Book of Revelation, p. 5.

${ }^{4}$ GARCEZ, L., Apocalipsis, p. 13.
} 
O cristianismo, desde o seu início, foi um movimento apocalíptico profético. ${ }^{5}$ Ele tem suas raízes muito profundas no discipulado instituído por Jesus Cristo. Fiel à sua tradição apostólica, procurou estabelecer uma ponte entre os diversos movimentos populares judaicos e, com toda sua riqueza simbólica e teológica, contribuiu de maneira significativa para uma síntese da tradição profética e apocalítica do Antigo Testamento. ${ }^{6}$

A linguagem apocalíptica expressava o profundo sentimento de angústia que as comunidades joaninas passavam, sobretudo pela opressão, imposta pela dominação hegemônica do poder romano. Assim, a concepção apocalíptica emergiu por conta da disparidade entre as expectativas sobre o cumprimento das Escrituras e o real cenário em que estavam mergulhadas essas comunidades. ${ }^{7}$ As contradições entre a proposta de reino do império e a visão a partir da fé em Jesus Cristo para João é uma grande ameaça à identidade cristã. Por isso, ele faz uma releitura dos flagelos que desafiavam os cristãos, tendo como fundamento a experiência de fé no Ressuscitado.

\subsection{A Missão profética daquele que vê}

Nos primeiros versículos do livro do Apocalipse, João se apresenta como aquele que dá testemunho ( $\mu \alpha \rho \tau v \rho \varepsilon ́(\omega)$ de tudo que viu (ópó $\omega)$. Nesse sentido, $o$ ato de ver denota um profundo conhecimento de tudo o que ele descreve. Além disso, a literatura joanina adotou diversos verbos, que indicam o ato de

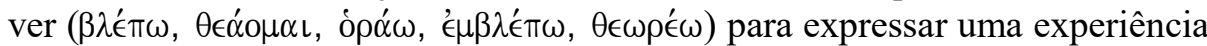
pessoal e profunda de algum personagem (Jo 1,31-34.35-39). Ele se coloca como servo da Palavra de Deus e de Jesus Cristo, na perspectiva profética (Ap

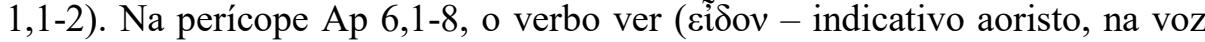
ativa, indicando o fato realizado) aparece quatro vezes nesses versículos. ${ }^{8}$ Portanto, João conhecia muito bem as calamidades que afligiam as comunidades cristãs, às quais se dirigia. Seu testemunho está enraizado em convicções profundas, que ele deseja compartilhar com todos e transformá-las em ações concretas.

O livro do Apocalipse reflete o pensamento não apenas de seu autor, mas sim, do movimento apocalíptico cristão. Os discípulos de Jesus Cristo, que faziam parte deste movimento, fundamentavam-se no movimento profético

\footnotetext{
${ }^{5}$ SLATER, T. B., Christ and Community, p. 74.

${ }^{6}$ WATSON, D. F., The Intertexture of Apocalyptic Discourse in the New Testament, p. 245.

${ }^{7}$ HELLHOLM, D., The problem of apocalyptic genre and the Apocalypse of John, p. 22.

${ }^{8}$ COLLINS, J. J., Apocalyptic Literature, p. 836.
} 
apocalítico do pós-exílio. Dele faziam parte lideranças, que se sentiam desafiadas em sua missão apostólica nas comunidades cristãs do primeiro século. ${ }^{9}$ João recolheu as tradições apocalípticas do judaísmo e do cristianismo judaico, transformando-as em um elemento de resistência diante da helenização do cristianismo e da institucionalização do absolutismo da ideologia política, cultural e religiosa do império romano. ${ }^{10}$

$\mathrm{O}$ vidente de Patmos, como João se identifica, escreve para sete comunidades cristãs diferentes e, cada uma, enfrenta flagelos ou desafios distintos. A genialidade do Apocalipse é sua habilidade de falar distintamente dessas situações de sofrimento na sua singularidade e, ao mesmo tempo, articular o que João espera, isto é, que a ética cristã seja adotada na sua radicalidade por todos os discípulos e discípulas, como uma resistência ao absolutismo da ideologia imperial. ${ }^{11}$ A profecia apocalítica é colocada simultaneamente, imprimindo um caráter único de leitura da realidade.

$O$ relato de João em linguagem profética-apocalíptica é uma mensagem de esperança para os discípulos de Jesus de seu tempo. Ele recorreu a esta linguagem simbólica para fortalecer os cristãos que, marginalizados, viam seus sonhos de construir fraternidade, sofrendo ameaças contínuas em uma realidade injusta e violenta. Jesus é apresentado sob a imagem do Cordeiro que desvela a origem dos flagelos, que retira o véu da verdade oculta por trás dos fatos, como caminho para reconstruir uma nova realidade. ${ }^{12}$

\subsection{Ap 6,1-8: o Cordeiro abre os selos que desvelam os flagelos}

O livro do Apocalipse se apresenta com uma característica literária particular. Os eventos importantes sãos descritos a partir de uma estrutura repetitiva do número sete: as sete Igrejas da Ásia Menor, os sete selos, as sete trombetas, os sete flagelos ou pragas. ${ }^{13} \mathrm{O}$ capítulo 6 apresenta o rompimento dos sete selos, que permitem ao leitor ver os flagelos. Porém, a micronarrativa Ap 6,1-8 apresenta personagens e um cenário distinto da segunda parte do capítulo. Somente os quatro primeiros selos são acompanhados do surgimento de cavalos e cavaleiros. A abertura dos selos ocorre em duas partes. Primeiro, se rompem os quatro primeiros selos que têm um papel importante nessa

\footnotetext{
${ }^{9}$ RICHARD, P., Apocalipsis, reconstrucción de la Esperanza, p. 10.

${ }^{10}$ FIORENZA, E. S., The Book of Revelation, p. 6.

${ }^{11}$ WATSON, D. F., The Intertexture of Apocalyptic Discourse in the New Testament, p. 218.

${ }^{12}$ HERMS, R., An Apocalypse for the church and for the world, p. 169.

${ }^{13}$ STEFANOVIC, R., Revelation of Jesus Christ, p. 28.
} 
revelação, com o simbolismo dos quatro cavalos que trazem o mal a terra. Depois, os outros três selos se referem ao clamor dos mártires, que passaram por sofrimentos e tribulações. A abertura dos quatro primeiros selos representa os passos iniciais pelos quais Deus, por meio de Jesus Cristo, prepara o caminho para os discípulos entenderem a história, o julgamento do mal e a construção de um novo tempo, de uma nova realidade.

Segundo o autor do Apocalipse, o Cordeiro de Deus, Jesus Cristo, é o único que tem autoridade para abrir os selos, que escondem os flagelos (Ap 5,26). ${ }^{14} \mathrm{O}$ texto de Ap 6,1-8 descreve o cenário do Cordeiro, que rompe os selos e revela quatro flagelos que afligiam as comunidades para as quais João escreve: a guerra, a violência, com a pesada repressão militar, a fome, como consequência da exploração econômica, a morte, como resultado de um sistema político e econômico que não favorecia a vida. ${ }^{15}$

Segue a narrativa da perícope Ap 6,1-8 que forma uma unidade indicada pelos personagens e o lugar. No versículo seguinte os cavalos e cavaleiros desaparecem. Novos personagens são introduzidos e o novo ambiente é o altar que aprece em Ap 6,9.

A tradução a seguir da referida perícope procura refletir, na medida do possível, as nuanças do texto grego segundo a edição crítica de Nestle-Aland. Por conta da natureza sucinta desse trabalho, a tradução literal será apresentada de forma simples por versículo sem a segmentação do texto.

\section{Texto Grego}

\section{Tradução}

\begin{tabular}{|c|c|c|}
\hline v.1 & 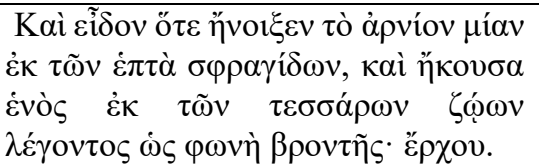 & $\begin{array}{l}\text { E Vi quando abriu o Cordeiro abriu } \\
\text { um de sete selos, e ouvi um os quatros } \\
\text { seres viventes dizendo como voz de } \\
\text { trovão: Vem. }\end{array}$ \\
\hline v.2 & 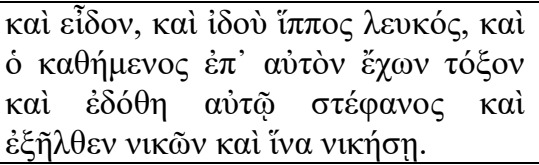 & $\begin{array}{l}\text { E vi, e eis (um) cavalo branco, e o } \\
\text { assentado sobre ele tendo (um) arco e } \\
\text { foi dada a ele (uma) coroa e saiu } \\
\text { vencendo e para que vencesse. }\end{array}$ \\
\hline v.3 & 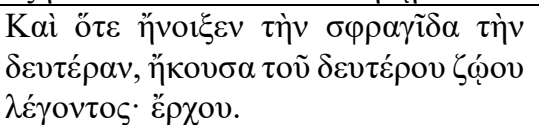 & $\begin{array}{l}\text { E quando abriu o selo segundo ouvi o } \\
\text { segundo ser vivente dizendo: Vem. }\end{array}$ \\
\hline
\end{tabular}

14 THOMAS, R. L., Revelation 1-7, p. 413.

${ }^{15}$ MOUNCE, R. H., The Book of Revelation, p. 118. 


\begin{tabular}{|c|c|c|}
\hline v.4 & 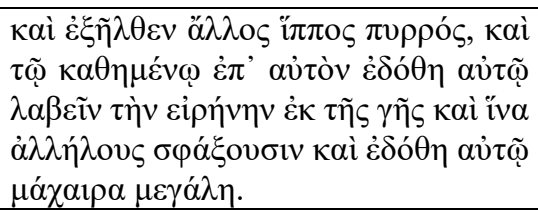 & $\begin{array}{l}\text { E saiu o outro cavalo vermelho e ao } \\
\text { assentado sobre ele foi dado a ele } \\
\text { tomar a paz da terra e para que uns aos } \\
\text { outros matassem e foi dada a ele (uma) } \\
\text { espada grande. }\end{array}$ \\
\hline v.5 & 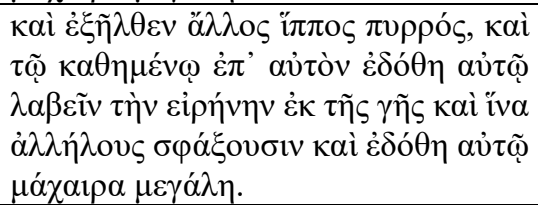 & $\begin{array}{l}\text { E quando abriu o selo terceiro, ouvi o } \\
\text { terceiro ser vivente dizendo: Vem. E } \\
\text { vi e eis (um) cavalo preto, e o } \\
\text { assentado sobre ele tendo (uma) } \\
\text { balança na mão dele. }\end{array}$ \\
\hline v.6 & 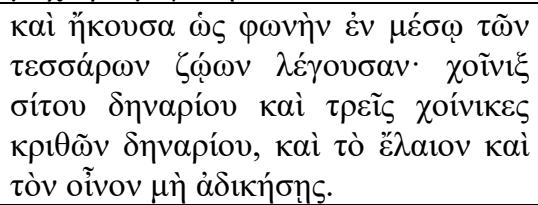 & $\begin{array}{l}\text { E ouvi como (uma) voz em meio dos } \\
\text { quatro seres viventes dizendo: (Uma) } \\
\text { medida de trigo por denário e três } \\
\text { medidas de cevada por denário, e o } \\
\text { azeite e o vinho não danifiques. }\end{array}$ \\
\hline v.7 & 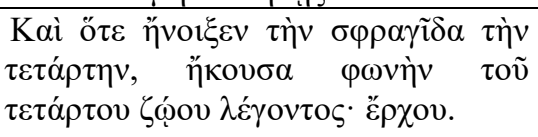 & $\begin{array}{l}\text { E quando abriu o selo quarto, ouvi a } \\
\text { voz do quarto ser vivente dizendo: } \\
\text { Vem. }\end{array}$ \\
\hline v.8 & 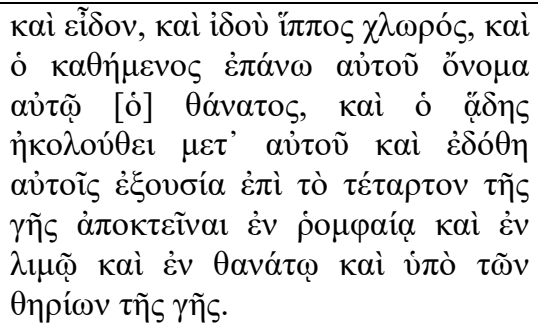 & $\begin{array}{l}\text { E vi, e eis (um) cavalo amarelo, e o } \\
\text { assentado sobre ele (tinha o nome) } \\
\text { Morte, e o Hades o seguia com ele e } \\
\text { foi dada a eles autoridade sobre a } \\
\text { quarta parte da terra para matar com a } \\
\text { espada e com a fome e com a morte e } \\
\text { por todas as feras da terra. }\end{array}$ \\
\hline
\end{tabular}

Como mencionado anteriormente, o verbo ver ( $\varepsilon i \tilde{\delta} \delta$ ov) especifica o papel profético de João: ele permanece como testemunha do drama que será apresentado, ${ }^{16}$ principalmente na teologia joanina, onde a testemunha é aquela que fez a experiência do "mistério". O autor destaca que seu papel é ser testemunha fiel dos eventos que estão para acontecer. A cada selo que se abre não é revelado o conteúdo da mensagem escrita no livro, estando ele escrito por fora e por dentro (Ap 5,1). Contudo, importantes ações ocorrem em inquestionável correspondência com a mensagem revelada.

Os quatro primeiros selos que são abertos têm um elemento em comum: cada um deles é precedido de um anúncio de um ser Vivente ( $\zeta \omega \omega v)$, seguido da identificação da cor do cavalo que surge e do cavaleiro, que tem um poder

${ }^{16}$ THOMAS, R. L., Revelation 1-7, p. 414. 


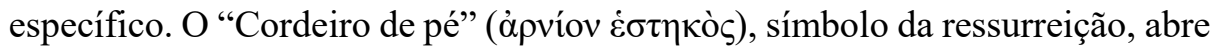
cada selo em sequência. Tais selos mantêm o livro fechado, denotando que somente quem tem autoridade pode revelar o conteúdo da mensagem. Imediatamente após a abertura do selo, João ouve a voz do primeiro dos Viventes, como estrondo de trovão, lembrando a teofania do Sinai, quando o Senhor Adonai entrega a Torá ao povo escolhido.

A forte voz do ser vivente se expressa com uma ordem ou convocação ao cavaleiro: vem (o verbo ( $\check{\rho} \rho \circ \mathrm{ov}$ ) encontra-se na forma imperativa, presente). A resposta do cavaleiro ao comando é imediata. E a imagem que João vê e testemunha é o primeiro flagelo. O cavalo branco ( $\lambda \varepsilon v \kappa o ́ \varsigma)$ é símbolo da força militar romana, cujo cavaleiro traz o arco, seu instrumento de guerra. Ele recebe a coroa ( $\sigma \tau \varepsilon \dot{\varepsilon} \varphi \alpha \nu \circ \varsigma)$, símbolo do poder real, e parte como um vencedor ( $(1 \kappa \eta ́ \sigma \eta ̣)$. A vinda do cavalo branco emerge de forma emblemática, pois a cor branca no Apocalipse também é atribuída ao Cordeiro e aos mártires. ${ }^{17}$ No entanto, aquele que vê, isto é, João, é capaz de discernir e identificar as ações que produzem o mal (aqueles que portavam arcos traziam também as flechas nas contínuas ameaças de guerra).

Quando o Cordeiro abre o segundo selo, João é testemunha ocular de que surge outro cavalo, de cor vermelha ( $\pi \nu \rho \rho o ́ s)$, cujo cavaleiro tem o poder de tirar a paz da terra, portando uma espada. Sua presença instaura um tempo de

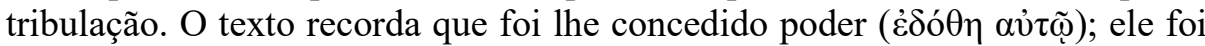
designado para esta missão por alguém, que não é o Cordeiro. $O$ domínio de onde a paz foi retirada é especificado pelo termo $\tau \tilde{\eta} \varsigma \gamma \tilde{\eta} \varsigma$ (da terra). O impacto deste selo tem dimensões universais. $O$ verbo massacrar/assassinar

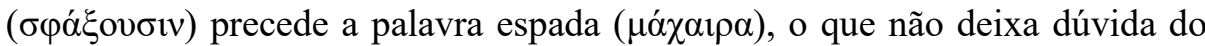
flagelo que este provoca na terra. ${ }^{18}$ Simbolicamente, o cavaleiro recebe autoridade e a tarefa de provocar derramamento de sangue.

A cor vermelha sugere a natureza da segunda capacidade, isto é um tempo de cruel matança e derramamento de sangue. Este cavaleiro é um

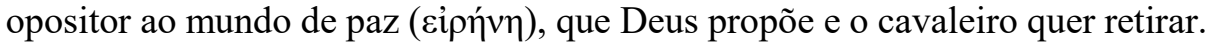
Este flagelo tem um impacto também na paz interior da comunidade, pois a presença militar romana anunciava uma paz falsa, garantindo uma segurança que não existia. ${ }^{19}$

O processo de quebrar ou abrir os selos revela o conteúdo da mensagem apocalíptica com um simbolismo dramático e vivido em sintonia com as

${ }^{17}$ THOMAS, R. L., Revelation 1-7, p. 422.

18 THOMAS, R. L., Revelation 1-7, p. 428.

19 THOMAS, R. L., Revelation 1-7, p. 429. 
profecias do Antigo Testamento. Esta linguagem era familiar às comunidades, que o Messias anunciado, viria de forma humilde, montado em um jumento para quebrar o arco dos guerreiros: "Eis que vem teu rei ao teu encontro; ele é justo, ele salva; é humilde e vem montado num jumento, um potro, cria de jumenta. Eliminará os carros de Efraim, os cavalos de Jerusalém; ele quebrará o arco de guerreiro, anunciará a paz às nações" (Zc 9,9-10). Para as comunidades cristãs essa linguagem era familiar e assim João recorda aos discípulos que em Jesus Cristo se encontra a esperança de um novo tempo.

À abertura do terceiro selo (Ap 6,5-6), segue-se uma ordem do terceiro Vivente, a qual revela um novo desenvolvimento chocante. É uma cena de pesar: surge o cavalo preto ( $\mu \varepsilon \dot{\lambda} \alpha \varsigma)$, a cor do lamento e do luto. A triste consequência que seu cavaleiro traz é a escassez de alimentos, o jugo da balança

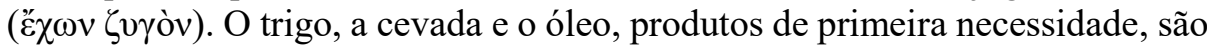
extremamente caros e diante dessa realidade econômica, somente os ricos podem se saciar. ${ }^{20}$

Após o segundo selo, o povo experimentou os sofrimentos da guerra. A fome, vinda com o terceiro cavaleiro, é uma das consequências da guerra. A

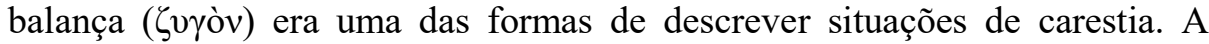
sociedade do primeiro século era basicamente agrária e, neste contexto, pesar na balança produtos de primeira necessidade realmente retrata uma situação de

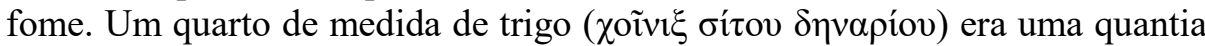
muito pequena para uma família, considerando que era o principal alimento no cotidiano. ${ }^{21}$ Além disso, o preço de um denário ( $\left.\delta \eta v \alpha \rho i ́ o v\right)$, que equivalia a um dia inteiro de trabalho de um homem, quando tinha a possibilidade de ser contratado para um trabalho, significava um preço muito alto.

Entretanto, há uma disparidade no preço do trigo com o óleo de oliva e o vinho, que deviam ser vendidos a um preço muito mais acessível. Tais produtos eram, em grande parte, consumidos pelos ricos, particularmente nas festas, já que o pobre consumia todo seu salário com os seus alimentos básicos.

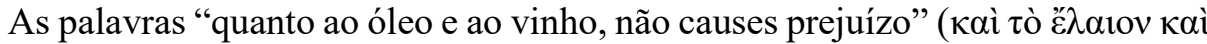

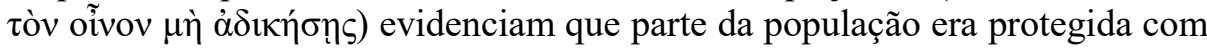
a garantia desses produtos. O óleo de oliva, por sua vez, era usado para lâmpadas ou para medicamento e unção, durante as festas. Certamente, havia uma grande discrepância entre o nível de vida de ricos e pobres, desiquilíbrio este que, aliás, continua a existir. O conforto e alegria das festas são retirados dos pobres trabalhadores, todavia os ricos passam ilesos pela dificuldade.

${ }^{20}$ SLATER, T. B., Christ and Community, p. 174.

${ }^{21}$ SLATER, T. B., Christ and Community, p. 176. 
Um aumento notável na gravidade da situação ocorre com a abertura do quarto selo. A cor esverdeada ( $\chi \lambda \omega \rho$ ós) do cavalo tem uma estreita relação com

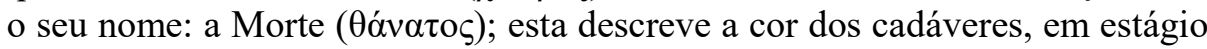
avançado de decomposição. O cenário é de terror, pois ele aflige a quarta parte da terra, com o extermínio pela espada, fome, peste e feras da terra (Ap 6,7-8).

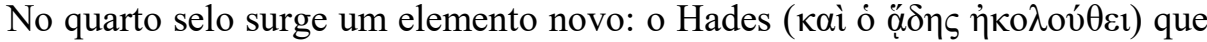
acompanha a morte. Colocado ao lado da morte, esclarece que a implicância da morte vai além do físico. Aparentemente o Hades exerce o papel de manter a

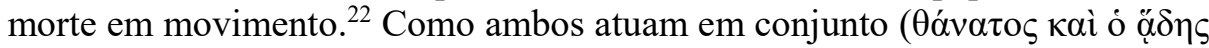

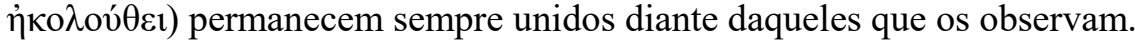

O quarto selo é o único que dá nome ao montador do cavalo ( $\theta \alpha ́ v \alpha \tau o \varsigma)$ e seu acompanhante (ó ọ̊ $\delta\rceil)$ ). E assim completa a série dos flagelos revelados pelo Cordeiro. Por isso, haverá o grande julgamento, que eliminará esses males, para poder reconstruir a esperança. As calamidades são colocadas na visibilidade de todos. ${ }^{23} \mathrm{~A}$ abertura dos selos assinala que a guerra com sua violência, aflige uma grande parte da humanidade: a quarta parte da terra será

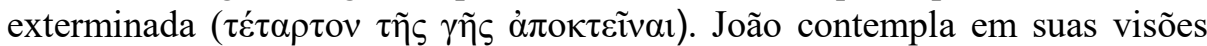
todos esses sofrimentos, que continuarão nos próximos três selos. A grande interrogação que permanece: como o livro do Apocalipse relaciona esses sofrimentos com a abertura dos selos por Jesus o Cordeiro de Deus?

O livro do Apocalipse nasce num momento em que muitas comunidades cristãs passavam por diversas ameaças e perseguições em seu cotidiano. E nesse contexto, sua mensagem é um convite aos cristãos para resistirem e reconstituírem a esperança. ${ }^{24}$ Algumas delas eram expostas ao perigo de prisão e morte (Ap 2,8; 3,7), outras, pressionadas a negarem a fé em Jesus Cristo. E resistir poderia ter como consequência o martírio. Também havia situações em que a causa de sofrimento era a dificuldade de ser fiel à identidade cristã diante do ethos da cultura dominante, que os excluíam. Assim, a mensagem apocalíptica aponta para Jesus como Aquele que vem para inaugurar um novo tempo, um novo futuro, que traz esperanças àqueles que estão sofrendo sobre os flagelos da morte pela espada, fome, peste e pela opressão das feras da terra (Ap 6,8).

22 THOMAS, R. L., Revelation 1-7, p. 437.

${ }^{23}$ SLATER, T. B., Christ and Community, p. 177.

${ }^{24}$ PAGÁN, S., Apocalipsis, p. 45. 


\section{Identificar a origem do mal como caminho de mudança}

O gênero apocalíptico, mais que um gênero literário, é uma atitude daqueles que resistem ao poder do mal, personificado pelos poderes imperialistas e suas divindades. Além da resistência, caracteriza-se por uma atitude de fidelidade a Deus, como único soberano e Senhor. É também uma forma de testemunho, daqueles que preferiam morrer, a assumirem os valores de uma sociedade organizada a partir da dominação, exploração e morte. ${ }^{25}$ É a linguagem de um grupo de cristãos que caminha pelos sofrimentos, com os olhos direcionados para o alto, para o Cordeiro que está no trono, porque Ele é sua única esperança.

A linguagem apocalítica profética, enquanto denúncia de sistemas sóciopolítico e econômico injustos, assinala que os poderes deste mundo são imperfeitos, limitados e frequentemente se identificam com os poderes satânicos, que oprimem os santos. Porém, o poder do mal não será a última palavra, ele sofrerá as penalidades do Cordeiro, que reina neste mundo, porque já está no trono. Como profecia, interpreta a situação presente, tornando visível a origem dos males e flagelos que afligem a humanidade. ${ }^{26}$

Diante da dimensão global da disseminação do coronavirus, muito tem se questionado acerca das mudanças e transformações para um futuro mais saudável da humanidade. Para evitar futuras pandemias de igual proporção, mudanças de hábitos se fazem necessárias e, sobretudo, de modelos econômicos que possibilitem a sustentabilidade do planeta. A tradição bíblicoapocalíptica interpreta os grandes flagelos como consequências de nossas omissões e más ações. Muitos dados científicos têm nos alertado, nas últimas décadas, que a insalubre indústria aviária e de piscicultura, por exemplo, tem um grande potencial para provocar sucessivas pandemias. ${ }^{27}$

Estudos científicos realizados para investigar a causa da gripe aviária, que infectou muitas pessoas na Ásia e na Europa de 2006 a 2018, revelam que a origem dessa epidemia são as condições nocivas da indústria aviaria, seja no manejo das aves ou no seu abate, pois são extremamente insalubres e colocam em sério risco a saúde pública. O confinamento das aves, os criadouros próximos de grandes centros urbanos, alimentação não natural, são elencados como as possíveis causas da origem e mutação de diversos vírus, que

\footnotetext{
${ }^{25}$ UBÍÑA, J. F., El imperio romano como sistema de dominación, p. 89.

${ }^{26}$ BLANCO, C., El pensamiento de la Apocalíptica Judía, p. 59.

${ }^{27}$ FEARE, C. J.; YASUE, M., Asymptomatic infection with highly pathogenic avian influenza H5N1 in wild birds, p. 2.
} 
contaminam os seres humanos. ${ }^{28}$ Outro grave problema detectado por esses estudos foi que as indústrias aviárias e de piscicultura se desenvolvem em ambientes muito próximos entre si, de forma que o abate de aves infectadas servia de alimento aos peixes. O descuido com normas sanitárias e de higiene fazem com que tais alimentos, contaminados e perigosos para a saúde, sejam colocados em grande escala no mercado. Além disso, os vírus portados por esses animais, que originalmente são inofensivos para estas espécies, por conta do contínuo contato com seres humanos, passam por mutações, ocasionando doenças para as pessoas.

Essas investigações científicas apontam que ocorrem frequentes mutações nesses vírus, ocasionando novas epidemias em proporções cada vez maiores. Análises realizadas acerca dessas mutações demonstram que tais vírus têm se adaptado em seres humanos e se revelado muito resistentes aos vários tipos de drogas usadas em tratamentos ao ser humano. Profissionais da saúde alertam que esse processo de mutação coloca continuamente em risco a vida humana e sucessivamente, pode provocar novas pandemias, se a indústria aviária e de piscicultura não mudarem a forma de produção desses alimentos. ${ }^{29}$ As vacinas desenvolvidas para o controle dessas epidemias não foram muito efetivas.

A disseminação do novo coronavírus tem nos ensinado que vencer esta pandemia, vai além de encontrar uma vacina que nos torne imunes ao vírus. Aprendemos que é preciso cuidar da vida humana e da natureza, enquanto estão com saúde. Observamos que preservar a saúde custa muito menos que investir em equipamentos extremamente caros, que não evitam um número de morte altíssimo. $\mathrm{O}$ índice de morte, mesmo para aqueles que tiveram acesso a leitos de UTI, é exorbitante. Reduzir os riscos de contágios, evitar que as pessoas fiquem doentes, pode impedir desperdícios econômicos e garantir mais eficiência para vencer a pandemia. A velocidade com que se produz animais, em larga escala e às custas de depredação da natureza, com a finalidade de obter grandes lucros, tem se demonstrado algo extremamente perigoso para a vida humana e a do planeta.

Vivemos, a nível mundial, numa atmosfera de angústia, medo, incertezas e um isolamento forçado, sem precedentes. Olhando para essa realidade, sob a perspectiva da profecia apocalíptica, podemos entrever que um grande flagelo

\footnotetext{
${ }^{28}$ YANG, L. et al., Genesis and Spread of Newly Emerged Highly Pathogenic H7N9 Avian Viruses in Mainland China, p. 3.

${ }^{29}$ YANG, L. et al., Genesis and Spread of Newly Emerged Highly Pathogenic H7N9 Avian Viruses in Mainland China, p. 11.
} 
não surge por acaso e desencadeia vários outros. Assim como o texto de Ap 6,1-8 estabelece que o flagelo da guerra teve como consequência a violência, morte, fome e peste, a pandemia que presenciamos com o coronavirus tem provocado outras igualmente terríveis, tais como: empobrecimento, desemprego, fome, exclusão social e o sofrimento pela perda de tantas vidas humanas.

Autoridades do campo político e econômico parecem ter ignorado a opinião e os conhecimentos científicos que, por décadas, vêm alertando para os riscos de uma pandemia. O conhecimento científico trouxe esclarecimento, contudo, não foi capaz de gerar decisões ético-políticas que evitassem o flagelo coronavirus e de outras possíveis e breves pandemias. ${ }^{30} \mathrm{~A}$ ciência nos apresenta modelos teóricos que explicam as origens e as causas de como esses fenômenos são produzidos. A falta de programas sócio-políticos para administrar a grave crise pela qual passamos não ocorre por falta de conhecimento e sim pela grave perda de valores humanos, éticos e morais, tendo em vista salvaguardar os interesses de grandes grupos econômicos.

A pandemia tem levado toda humanidade a se confrontar com novas sabedorias de vida, de uso do conhecimento científico, fundamentado na solidariedade; com modelos econômicos ecologicamente sustentáveis, em decisões que gerem a fraternidade, com cuidado aos mais vulneráveis; com a defesa dos direitos de grupos e povos mais ameaçados, por não terem acesso aos meios que os protegem deste mal. O longo período, de acelerada disseminação, tem desafiado e surpreendido muitas instituições e a Igreja. Tal realidade nos faz pensar que as propostas do Papa Francisco para cuidar da casa comum e de uma ecologia integral são urgentes. ${ }^{31}$

\section{A manifestação divina que permite reconstruir a esperança}

O autor do livro do Apocalipse tinha consciência de que, para além das injustiças sociais, da dominação e exploração imperialista do poder romano, Deus estava presente no meio de seu povo. A literatura apocalíptica interpreta o momento histórico presente, sob a perspectiva das ações salvíficas de Deus no passado. Ao projetar um futuro de esperança, tem um olhar de fé retrospectivo, recordando que Deus é Aquele que, continuamente, na história, restaura a obra da Criação. ${ }^{32}$ A Apocalíptica em nenhum momento se

\footnotetext{
${ }^{30}$ PIMENTEL, A. M., En búsqueda de los valores perdidos, p. 26.

${ }^{31}$ LS 4.

${ }^{32}$ CUVILLIER, E., O Apocalipse de João, p. 512.
} 
desvincula da história. O movimento apocalíptico cristão compreende-se como histórico. Seu olhar e propostas para superar os flagelos são postulados a partir do Cordeiro, isto é, de uma solidariedade fraterna que se preocupa com a família humana em todos os aspectos: espiritual, político e econômico.

A apocalíptica é a literatura de resistência de todos aqueles que são perseguidos por sua fidelidade a Deus. Expressa-se por meio de uma linguagem simbólica, a fim de ajudar as comunidades dos discípulos de Jesus Cristo a participarem ativamente da missão transformadora das realidades de sofrimento. O mal não tem a última palavra. Deus propiciará um final glorioso, um momento de graça, que será como um céu na terra. ${ }^{33}$ Superar os flagelos supõe a transformação das estruturas enfermas, injustas e destrutivas que rompem com as violações sistemáticas dos direitos básicos.

A Igreja, descrita no Apocalipse, está em profundo conflito com os poderes deste mundo. A comunidade do Ressuscitado está em conflito com o poder greco-romano, origem de tantos flagelos. A comunidade sofre para proclamar Jesus Cristo como seu único soberano, frente ao culto imperial a César. É uma Igreja que se identifica com as práticas do Cordeiro imolado, pois atua para construir o novo céu e a nova terra (Ap 21,1-8). Trazendo para nossa realidade atual de pandemia, o olhar cuidadoso e benevolente do Cordeiro impele-nos a buscar uma conversão humana e ecológica como possiblidade de superar essa nova crise. É necessário pautar novos caminhos, a fim de sanar as estruturas de uma economia global injusta, com práticas destrutivas e que ameaçam o planeta.

A linguagem apocalíptica é uma forma de profecia. Ela constata que depois de cada experiência de calamidade, de sofrimento e morte é preciso se converter e voltar a Deus. ${ }^{34} \mathrm{~A}$ mudança de atitude é condição essencial para eliminar o mal. Uma interpretação em chave apocalíptica dos sofrimentos causados pelo Covid-19 acredita que esta pandemia não é um castigo divino. $\mathrm{Na}$ verdade, é um grande alerta nesse momento histórico que colocou o lucro dos grandes poderes econômicos como um deus e gerou corações insensíveis aos sofrimentos de grupos humanos. Como exemplos, podemos elencar os migrantes, refugiados forçados, empobrecidos, desempregados, minorias étnicas marginalizadas, os sem teto e tantos outros seres humanos que dependem da solidariedade para sobreviver.

Estes tempos de pandemia têm sido uma experiência única, inédita na história, no sentido de um isolamento simultâneo em diversas partes do mundo.

${ }^{33}$ CASALEGNO, A., E o Cordeiro vencerá, p. 26.

${ }^{34}$ GARCEZ, L., Apocalipsis, p. 17. 
Para muitos, esta é a primeira vez que se percebe o quanto a vida humana está conectada, o quanto dependemos da saúde do outro para sobreviver, o quanto a saúde pública depende do cuidado e empenho pessoal. Em diversos âmbitos da vida humana, devido à longa reclusão forçada, o digital substitui o presencial. De certa forma, esta comunicação intensa pelo mundo digital traz uma nova identidade cultural, pois conseguimos interagir com um mundo mais amplo que o presencial. Por outro lado, sofremos também as angústias de ver esta pandemia tomando proporções globais.

Se por um lado, as ferramentas do mundo digital têm facilitado a comunicação e a aproximação de pessoas em tempo de isolamento social, permitindo a tantos trabalhadores cumprirem com suas tarefas online, por outro lado, o acesso à tecnologia não é igual para todos. O impacto das desigualdades pode ser ainda maior para aqueles que não têm o devido acesso ao conhecimento do mundo digital. Esta pandemia poderá trazer mudanças radicais ao mundo do trabalho, com grandes embates econômicos, com a possibilidade do surgimento de novas categorias essenciais de trabalhadores e outras que não conseguirão sobreviver no mercado de trabalho remoto.

Há muitas previsões de que o mundo após a pandemia, não será o mesmo. Um dos exemplos são os encontros virtuais, que terão um grande impacto na indústria de viagens. Haverá mudanças no consumo de produtos pelos trabalhadores remotos. As grandes estruturas físicas de determinados setores econômicos poderão tornar-se desnecessárias, reduzindo custos de mão de obra. Esses são apenas alguns exemplos que podem, de um lado trazer benefícios, no entanto, por outro, serão geradores de desemprego em massa.

No sistema de atendimento da saúde já se propõe programas de telemedicina, reduzindo também o contato presencial de pacientes em estágios iniciais de determinadas doenças contagiosas. Há previsão de se desenvolverem aplicativos para exames médicos, com excelentes padrões de qualidade, pois eles poderão acelerar os cuidados dos pacientes, integrando-os com atenção presenciais quando necessárias. Programas de telemedicina já existem em países mais desenvolvidos. Tais mudanças nos desafiam e nos questionam nosso cuidado pastoral, enquanto Igreja: o digital pode substituir os encontros pessoais com a comunidade de fé, com o anúncio da Palavra? O excesso de uso do mundo digital também pode nos distanciar das pessoas e aumentar a indiferença e a insensibilidade diante da dor do outro?

A experiência de uma pandemia nos fez constatar que também somos capazes de praticar a solidariedade em igual dimensão. Nos sensibilizamos com a espera de tantas outras pessoas por notícias de que a tempestade vai passar. 
Somando esforços ao redor do mundo, encontraremos respostas para este flagelo. A presente crise nos conecta com tantas pessoas, com as quais temos em comum valores humanos e desejos de superar este sofrimento, com gratidão por aqueles que se empenham em pesquisas científicas para encontrar a cura, coragem para mudar hábitos de consumo desnecessário, solidariedade com os mais vulneráveis e um maior cuidado com o meio ambiente.

O texto de Ap 6,1-8, assim como todo o livro do Apocalipse, tinha como objetivo congregar as comunidades do Senhor Ressuscitado a buscarem saídas para o bem comum. As propostas pedagógicas para as comunidades da Ásia Menor consistiam, primeiramente, em consolar os que estavam sofrendo por conta dos inúmeros flagelos, para assim convidá-los a resistirem e a manterem a esperança nas práticas de misericórdia do Cordeiro.

\section{Conclusão}

Falar da esperança, implicava em convidar todos os discípulos de Jesus Cristo a construírem uma ética de resistência incansável e desobedecerem às práticas de morte do poder imperialista reinante. Uma das práticas políticaseconômicas do império romano para se perpetuar no poder era o desprezo pelas culturas locais, impondo uma cultura global. A dominação também criou mecanismo de imobilização social, reprimindo todas as manifestações locais de luta por justiça. É nesse contexto que surge a literatura apocalíptica cristã. Esse estilo próprio possibilitou o uso da linguagem simbólica, poética e imaginativa, compreensíveis aos seus interlocutores. Isso, para encorajá-los a enfrentar, com criatividade, a dominação, a peste, os flagelos da guerra e a morte em massa, que se escondiam por traz da propaganda da falsa Pax Romana. Uma aproximação com a mensagem do Apocalipse nos ajuda a recuperar a consciência de termos que tecer redes de convivência humana que sejam geradoras de uma solidariedade global. Que elas nos ajudem a conviver com as diferenças e a encontrar caminhos para superar a indiferença, o descaso e a insensibilidade diante da morte de milhares de pessoas. A pandemia nos tem ensinado que temos que aprender a apreciar e a cultivar a interdependência própria para reconstruir a esperança.

O texto de Ap 6,1-8 denuncia o modelo econômico da época que levou a um empobrecimento de grande parte da população, sendo portanto, as raízes de muitas mazelas daquele tempo. Sua crítica profética faz um forte apelo para uma transformação radical e eminente. Tais mudanças deveriam ocorrer em breve (Ap 1,1), pois aqueles que seguem o Cordeiro Imolado opõem-se 
radicalmente aos seguidores do dragão. A visão apocalítica do futuro fundamenta-se na esperança de que Deus é cuidadoso e benevolente com a obra da Criação. Ele aponta caminhos para uma solidariedade fraterna. A crise atual nos chama a uma conversão radical para sairmos dela melhores, ou seja, com propostas a níveis locais, nacionais e globais de um desenvolvimento humano integral, com políticas econômicas, que não visem apenas lucro e sim, o cuidado com a família humana e com o meio ambiente.

Segundo Francisco, a principal causa da escassez, da pobreza e da injustiça é o modelo econômico vigente, que prioriza o dinheiro, a manutenção das dívidas em todos os níveis, colocando a vida, em segundo plano. Neste sentido, a mensagem do Apocalipse se apresenta ainda contemporânea a esses tempos de pandemia, quando o clamor pela vida, pela dignidade, por uma economia ecologicamente sustentável é o mesmo que Deus espera que seja ouvido, sobretudo por aqueles que depositam sua fé e sua esperança no Cordeiro Imolado.

\section{Referencias bibliográficas}

BLANCO, C. El pensamiento de la Apocalíptica Judía. Ensayo FilosóficoTeológico. Madrid: Trotta, 2013.

COLLINS, J. J. Apocalyptic Literature. New York: Oxford University Press, 2014. CASALEGNO, A. E o Cordeiro vencerá. São Paulo: Loyola, 2017.

CUVILLIER, E. O Apocalipse de João. In: MARGUERAT, D. Novo Testamento: história, escritura e teologia. São Paulo: Loyola, 2009. p. 493-514.

FEARE, C. J.; YASUE, M. Asymptomatic infection with highly pathogenic avian influenza H5N1 in wild birds: how sound is the evidence? Virology Journal, v. 96, n. 3, p. 3-96, nov. 2006.

FIORENZA, E. S. The Book of Revelation: Justice and Judgment. Minneapolis: Fortress Press, 1998.

FRANCISCO, PP. Carta Encíclica Laudato Sí: sobre o cuidado da casa comum. São Paulo: Paulus, 2019.

GARCEZ, L. Apocalipsis: uma pedagogia de resitencia y esperanza. Revista SIWO, v. 5, n. 4, p. 11-40, jul./set. 2011.

GIRBÉS, E. A. El Apocalipsis de San Juan: Lectura Teológico-Litúrgica. Navarra: Editorial Verbo Divino, 2013. 
GONZAGA, W. Ap 19,1-8: Profetismo na Liturgia. Atualidade Teológica, v. 22, n. 60, p. 566-585, set./dez. 2018.

HELLHOLM, D. The problem of apocalyptic genre and the Apocalypse of John. In: COLLINS, A. Y. (Ed.). Early Christian Apocalypticism: genre and social setting. Decatur: Scholars Press, 1986. p. 13-64. (Semeia, 36).

HERMS, R. An Apocalypse for the church and for the world: The narrative Function of the Universal Language in the Book of Revelation. Berlin / New York: Walter de Gruyter, 2006.

MOUNCE, R. H. The Book of Revelation: The New International Commentary on the New Testament. Grand Rapids, Michigan: William B. Eerdmans Publishing Company, 1998.

NESTLE-ALAND. Novum Testamentum Graece. 28 ed. Stuttgart: Deutsche Biblegesellschaft, 2012.

PAGÁN, S. Apocalipsis: Interpretación eficaz hoy. Barcelona: Editorial Clie, 2012. PIMENTEL, A. M. En búsqueda de los valores perdidos. Revista Aurora, n. 2, p. 25-26, 2020.

RICHARD, P. Apocalipsis, reconstrucción de la Esperanza. Caracas: Ed. San Pablo, 2001.

SLATER, T. B. Christ and Community. A Socio-Historical Study of the Christology of Revelation. Sheffield: Sheffield Academic Press, 1999.

STEFANOVIC, R. Revelation of Jesus Christ: commentary on the Book of Revelation. Berrien Springs: Andrews Universtity Press, 2002.

THOMAS, R. L. Revelation 1-7: An Exegetical Commentary. Chicago: Mood Press, 1992.

UBÍÑA, J. F. El imperio romano como sistema de dominación. POLIS, Revista de ideas y formas políticas de la antigüedad clásica, n. 18, p. 75-114, 2006.

YANG, L. et al. Genesis and Spread of Newly Emerged Highly Pathogenic H7N9 Avian Viruses in Mainland China. Journal of Virology, v. 92, n. 23, p. 1-13, dez. 2017.

WATSON, D. F. The Intertexture of Apocalyptic Discourse in the New Testament. Atlanta: Society of Biblical Literature, 2002. 


\section{Gilvan Leite de Araujo}

Doutor em Teologia Bíblica pela Pontificia Università San Tommaso d'Aquino de Roma Docente em Teologia na Pontifícia Universidade Católica de São Paulo Docente no Instituto Superior em Filosofia Sede da Sabedoria da Diocese de Osasco São Paulo / SP - Brasil E-mail: gilvanleite@libero.it

\section{Izabel Patuzzo}

Doutoranda em Teologia Bíblica Pontifícia Universidade Católica de São Paulo

São Paulo / SP - Brasil

E-mail: isabellapatuzzo@hotmail.com

Recebido em: 12/01/2020

Aprovado em: 24/06/2021 